\title{
Large Pineal Meningioma Causing Loss of Vision in a Teenager
}

\author{
Mohammad Sami Walid, ${ }^{\mathrm{a}, \mathrm{b}}$, Mazen Sanoufa ${ }^{\mathrm{a}}$
}

\begin{abstract}
Pineal tumors are rare, especially meningiomas. We report an 18year old patient who presented with headaches, vision problems, walking difficulty, and drowsiness, who had a large pineal tumor that was resected. The tumor was a meningioma, WHO grade one. After surgery, the patient's vision did not significantly improve except for some peripheral vision.
\end{abstract}

Keywords: Pineal tumor; Vision loss

\section{Introduction}

The pineal body (epiphysis) is a small $(8 \mathrm{~mm})$ reddish-gray body that lies in the depression between the superior colliculi attached to the roof of the third ventricle near its junction with the mid-brain. In early life it has a glandular structure which reaches its greatest development at about the seventh year. After puberty, the glandular tissue gradually disappears and is replaced by connective tissue [1].

Large pineal tumors are rare [2] and because of their midline location usually compress the cerebrospinal fluid circulatory channels leading to hydrocephalus or displace adjacent neurological pathways causing bilateral symptomatology.

\section{Case Report}

An 18-year-old female developed headaches, vision problems, walking difficulty, and drowsiness. MRI of the brain

Manuscript accepted for publication June 15. 2010

${ }^{\mathrm{a}}$ Medical Center of Central Georgia, Macon, GA, USA

${ }^{\mathrm{b}}$ Corresponding author: Medical Center of Central Georgia, Macon, GA, USA. Email: mswalid@yahoo.com

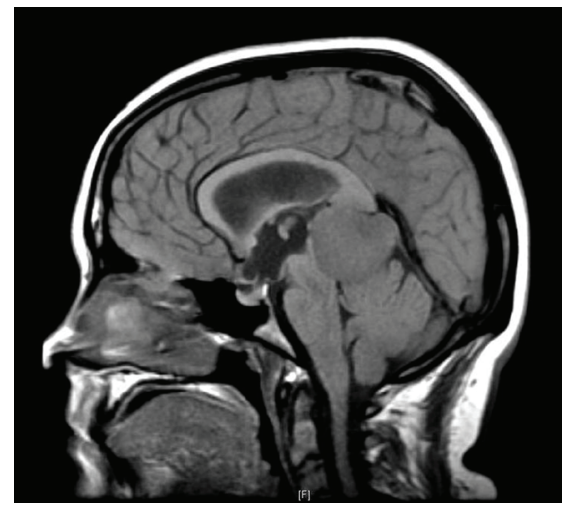

Figure 1. Brain MRI, sagittal view.

showed a large pineal mass tumor (Fig. 1-3). The patient, because of hydrocephalus, underwent ventriculostomy. At the time of ventriculostomy, biopsy of the mass could not be performed. The patient was taken back to the operation room and a stereotactic brain biopsy was obtained. Pathol-

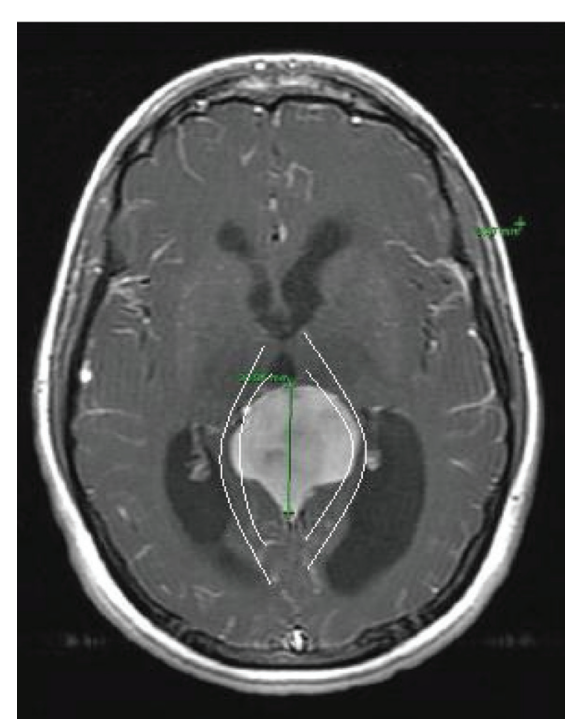

Figure 2. Brain MRI, transverse view. Imposed lines represent visual pathways. 


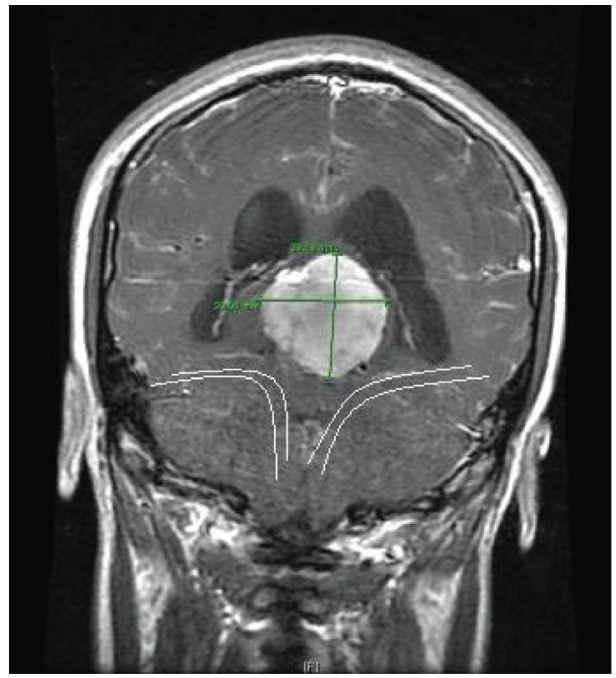

Figure 3. Brain MRI, coronal view. Imposed lines represent auditory-vestibular pathways.

ogy showed a fibrous meningioma, WHO grade one. Embolization of the tumor was performed prior to proceeding with craniotomy for tumor resection. After treatment, her vision did not significantly improve except for some peripheral vision.

\section{Discussion}

Pineal tumors can be divided mainly in germinomas and other tumors. Primary intracranial germ-cell tumors arise in the midline of the brain in the diencephalon [3]. The peak incidence occurs during the second decade of life [3]. Meningiomas are uncommon tumors and more rarely encountered in the pineal region and in children [4].

Pineal tumors can present with a myriad of symptoms due to their centralized location in the brain. Bilateral hearing and vision impairment has been frequently associated with pineal tumors [5-9].

Acoustic and vision relay pathways pass closely adjacent to the pineal body. Displacement of these structures may be responsible for the hearing and vision problems reported with these tumors.

Nowadays, germinomas can be cured by radiotherapy and chemotherapy without surgical resection but the other pineal region tumors are primarily treated by surgical resection [10].

Pineal tumors should always be suspected in young patients presenting with a combination of neurological signs suggesting hydrocephalus and midline injury as well as sleepiness and and visuo-auditory-vestibular impairment.

\section{References}

1. Human Anatomy: The Pineal Body. http://www.theodora.com/anatomy/the_pineal_body.html

2. Parwani AV, Baisden BL, Erozan YS, Burger PC, Ali SZ. Pineal gland lesions: a cytopathologic study of 20 specimens. Cancer 2005;105(2):80-86.

3. Peltier J, Vinchon M, Baroncini M, Kerdraon O, Dhellemmes P. Bifocal mixed germ-cell tumor with growing teratoma syndrome and metachronous mature metastases: case report. J Neurooncol 2008;90(1):111-115.

4. Matushita H, Pinto FC, Plese JP. Meningiomas of pineal region in children. Arq Neuropsiquiatr 2007;65(4A):1000-1006.

5. DeMonte F, Zelby AS, al-Mefty O. Hearing impairment resulting from a pineal region meningioma. Neurosurgery 1993;32(4):665-668.

6. Haque M, Ohata K, Tsuyuguchi N, Sakamoto S, Hara $\mathrm{M}$. A case of pineal region meningioma without dural attachment, presented with bilateral hearing impairment. Acta Neurochir (Wien) 2002;144(2):209-211; discussion 211

7. Missori P, Delfini R, Cantore G. Tinnitus and hearing loss in pineal region tumours. Acta Neurochir (Wien) 1995;135(3-4):154-158.

8. Ebina K, Suzuki S, Takahashi T, Iwabuchi T, Takei Y. Gangliocytoma of the pineal body. A case report and review of the literature. Acta Neurochir (Wien) 1985;74(34):134-140.

9. Takei H, Adesina AM, Mehta V, Powell SZ, Langford LA. Atypical teratoid/rhabdoid tumor of the pineal region in an adult. J Neurosurg 2009.

10. Radovanovic I, Dizdarevic K, de Tribolet N, Masic T, Muminagic S. Pineal region tumors--neurosurgical review. Med Arh 2009;63(3):171-173. 